Journal of Engineering and Applied Sciences 14 (Special Issue 8): 10291-10297, 2019

ISSN: $1816-949 \mathrm{X}$

(C) Medwell Journals, 2019

\title{
Experimental Investigation and Evaluation of Inclined Solar Air Heater
}

\author{
Mohammed A. Neama and Ayad T. Mustafa \\ Mechanical Department, College of Engineering, Al-Nahrain University, Baghdad, Iraq
}

\begin{abstract}
This research aims to investigate the temperature distribution and the effect of different parameters on the solar air collector performance. The parameters studied in the present research are the collector tilt angle $(\beta)$, the collector Height $(\mathrm{H})$ and the solar radiation Intensity (I). The flat plate solar air collector has been built and tested in Al-Nahrain University, Baghdad. The dimensions of the fabricated solar air collector are 120,100 and $20 \mathrm{~cm}$ in length, width and height, respectively. The test procedures were carried out by different instruments for the tilt angles of $30^{\circ}, 45^{\circ}, 60^{\circ}$ and $75^{\circ}$ and the collector height of 10 and $20 \mathrm{~cm}$. Analysis was implemented for the heat gain and thermal efficiency of the solar air heater. The obtained results show the maximum efficiency of $54 \%$ occurs for the tilt angle of $30^{\circ}$ and height of $10 \mathrm{~cm}$ while the maximum efficiency of $52 \%$ occurs for the tilt angle of $45^{\circ}$ and height of $20 \mathrm{~cm}$. It is found that the present solar collector supplies hot air up to $62^{\circ} \mathrm{C}$ for the height of $10 \mathrm{~cm}$ and the tilt angle of $30^{\circ}$. Generally, the results tend decrease when the tilt angles increase from $30^{\circ}-75^{\circ}$ and the collector height increase from $10-20 \mathrm{~cm}$.
\end{abstract}

$\underline{\text { Key words: Solar air heater, solar radiation, collector tilt angle, collector height, thermal efficiency, efficiency }}$

\section{INTRODUCTION}

Due to falling the fossil fuels reserves in the Earth concurrently with increasing the pollutant emission which has a negative effect on the world climate, alternative energy sources are become highly necessary. One of renewable energy which has non-depletion characteristic is the solar energy. The solar radiation as a beneficial energy which intercepts the Earth's surface are thousands times larger than the fossil resource. Consequently, solar energy could provide the world demand of energy and becomes the promising alternative energy source (Sayigh, 2012).

Solar thermal technologies, now a days are based on solar collectors. Solar collectors are receivers of solar irradiance utilized to convert the solar energy into the heat energy. Solar collectors receive solar radiation by two manners, either non-concentrated or concentrated radiation. Type of non-concentrating solar collector is the flat plate which can be applied for average temperatures up to $100^{\circ} \mathrm{C}$ above ambient temperature. Nature of flat plate collector absorption is including beam and diffuse solar radiation.

Operational process of the solar air heating is relying to an absorber plate that captures radiant energy. Then, absorbed energy is converting to heat which appears as temperature rise in an absorber plate. Due to convection heat transfer, temperature of airflow through the collector and over a heated absorber plate will increase. Thus, the solar air collector will converts inlet ambient air to outlet hot air. Figure 1 shows schematic of the solar air collector components with a structural tilt angle. Heated air

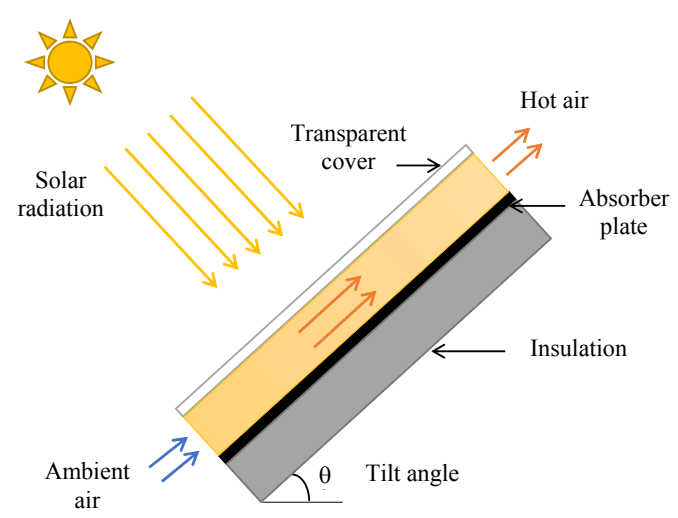

Fig. 1: Schematic of inclined solar air collector

produces from the solar air collectors can be utilized at different applications like (John and William, 2013; Kalogirou, 2004): space heating, solar water heating, solar chimney power plant, air conditioning and minerals/food drying.

The previous researches deal with the parameters affect the distribution of temperature and velocity of the thermal flow within the solar air collector. Ucar and Inalli (2006) investigated experimentally the solar air collector that has staggered absorber plates to increase heat transfer. Thermal performance and exergy balance for different collectors have evaluated. The results show that the greatest irreversibility is happening at the traditional flat plate solar collector where the efficiency is little. Yang et al. (2012) elaborated the effect of five parameters on the thermal efficiency of a flat plate air heater with

Corresponding Author: Mohammed A. Neama, Mechanical Department, College of Engineering, Al-Nahrain University, Baghdad, Iraq 
supplemental stagnation air layer. These parameters are heat resistance in the airflow, height of stagnation layer, transparent plate properties, absorber remittance and back thermal resistance. Experimental results revealed that diminishing heat resistance has a high effect in increasing thermal efficiency. Joudi and Farhan (2014) presented an experimental investigation of a solar air collector with $\mathrm{V}$ staggered absorber plate onthe rooftop of the greenhouse. The greenhouse heating load including soil heat storage was calculated where the soil participate by $13-19 \%$ of the heating load needed. Results show that for air mass rate of $0.012 \mathrm{~kg} \mathrm{sm}^{-2}$, air temperature of $18^{\circ} \mathrm{C}$ inside the greenhouse has provided $84 \%$ of the heat demand.

Ruskis et al. (2011) investigated different absorber plates in the solar air collector to compare the thermal efficiency. Influence of the collector length and the solar radiation on outlet temperature has tested. A polystyrol material covered on the tested absorber plate with different configurations. The efficiency of the air heater has determined. Aboltins and Palabinskis (2011) constructed a solar air collector with/without conventional material absorber plate to determine temperature distribution of airflow relying on the collector length and height. Experimental tests at the air velocity of $0.9 \mathrm{~m}$ $\mathrm{sec}^{-1}$ with sun tracking technique show that the temperature difference between the collector outlet and ambient air up to $11^{\circ} \mathrm{C}$ for the solar irradiance of $1000 \mathrm{Wm}^{-2}$. Palabinskis et al. (2008) constructed an experimental rig of the solar air collector with different materials for the absorber plate which permits for a comparative study at the same time. Two absorber materials of polycarbonate and polyvinylchloride films have investigated. Solar irradiance and velocity of the heated air have tested in $1.5 \mathrm{~m}$ length of the solar collector. A temperature difference between the collector outlet and ambient air is $6^{\circ} \mathrm{C}$. While Aboltins et al. (2009) used polystyrol material with the absorber plate in the solar air collector. The results show the temperature difference of $6^{\circ} \mathrm{C}$ occurs in the stationary collector and $10^{\circ} \mathrm{C}$ occurs in sun tracking collector at the air velocity of $0.55 \mathrm{~m} \mathrm{sec}^{-1}$.

Aboul-Enein et al. (2000) presented a mathematical model to predict the thermal performance of the solar air collector. This model analyzes air temperature variation with time when thermal storage used. Parameters of the collector dimensions, airflow rate, air temperature, storage material and thermal efficiency have investigated. It found that outlet air temperature decreases when the collector height increase. Esmailie et al. (2014) presented mathematical model validated experimentally for a solar air collector that built to analyze the thermal performance. Output air temperature and air velocity have proceeded to achieve in this model. The accuracy of the obtained results for the forced convection seems to be more than the natural convection when the mathematical model compared to experimental measurements. Wang et al. (2017) modeled mathematically a solar air collector with different configurations of semi-circular absorber plate. The solution of this model was carried out by using the FLUENT Software. The obtained results demonstrated that the outlet air temperature of the semi-circular absorber plate is more than that of the traditional flat plate and airflow and heat transfer is better for the semi-circular absorber plate. While Amraoui and Aliane (2018) modeled the flat plate solar air collector by ANSYS Workbench and solved by using ANSYS FLUENT. The simulation was carried out to predict the heat flow in the collector. Simulation results revealed the airflow and temperature distribution within the solar collector.

Summary: The convection heat flow produced over the solar absorber plate within the solar air collector was investigated experimentally and theoretically. Hence, it is essential to assess the solar air heater performance under the effect of natural convection flow with different parameters.

Research objectives: The present research aimed to study the effect of collector tilt angle, solar radiation intensity, distance along the collector and natural convection heat transfer on the solar air collector performance.

\section{MATERIALS AND METHODS}

Experimental setup and procedure: The main and significant part in the solar air collector is the absorber plate. In present study, the absorber plate is made of galvanized steel $(\mathrm{K}=60 \mathrm{~W} / \mathrm{m} . \mathrm{K})$ with $2 \mathrm{~mm}$ thickness which is covered with black coating to absorb maximum amount of solar radiation incidence. The dimensions of the solar air collector are 120,100 and $20 \mathrm{~cm}$ in length, width and height, respectively. It was fabricated by machines of cutting, twisting and pressing for the purpose of the bending and then it fixed to wooden enclosure by screws. Moreover, 21 small holes in three columns with seven holes in each were made on the plate by dimensions of away from the entrance and outlet region by $15 \mathrm{~cm}$, the distance between each hole and another is $15 \mathrm{~cm}$. The first column was made about $23 \mathrm{~cm}$ away from left edge of the collector, the second column is about $48 \mathrm{~cm}$ away from left edge also and the third column is about $27 \mathrm{~cm}$ away from right edge of the collector. These holes were prepared to be linked with nuts on the back side of the plate. Thin bolts by different heights were installed in the holes, first level of height is $20 \mathrm{~cm}$ and the second is $10 \mathrm{~cm}$. The reason dates back to fixing the thermocouples vertically on the bolts to measuring thermal layers and temperatures distribution within the collector. An insulation material of glass-wool $(\mathrm{K}=0.038$ $\mathrm{W} / \mathrm{m} . \mathrm{K}$ ) with $2.5 \mathrm{~cm}$ thick was used on the back of the plate and both sides of the absorber. The glass-wool with two layers $(5 \mathrm{~cm})$ was installed to decreasing thermal losses produce from the collector back and sides to environment. 


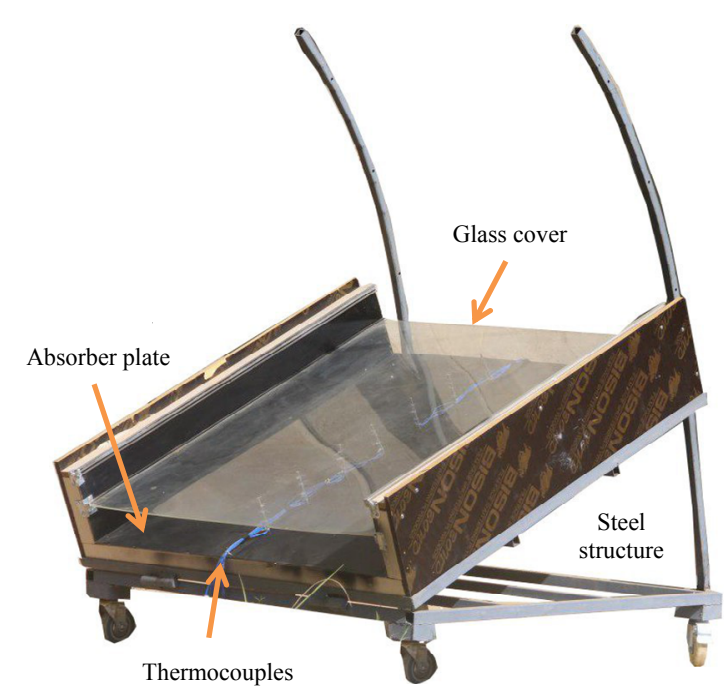

Fig. 2: Experimental model of solar air heater

To keep hot air passing through the solar air collector with less heat losses, a top cover has been used. In the present research, glass of $90 \%$ solar transmittance and $6 \mathrm{~mm}$ thickness was used to cover the collector. The solar air collector fixed on the moving frame which is capable of being moved via. two curved columns to compose four angles of $30^{\circ}, 45^{\circ}, 60^{\circ}$ and $75^{\circ}$. The glass-wool insulation layers were used in the base of the enclosure to fill the gap between the absorber plate and the enclosure. The absorber plate was connected with the enclosure by several bolts. The glass cover was fixed on the top of the enclosure and in the mid-way between the absorber plate and the top cover by using slots. The space between the absorber plate and the first cover of 10 or $20 \mathrm{~cm}$ represents the channel of hot airflow. It is an important thing in the solar collectors to tight an air leakage to decrease the environment effect on thermal performance and the solar collector efficiency. An assembly of the solar air collector on the steel structure is shown in Fig. 2 which utilizes in different cases of the tests procedure.

Experimental procedure: The tests were carried out outside the mechanical engineering laboratory at AL-Nahrain University, Baghdad (latitude of $33.33^{\circ} \mathrm{N}$ and longitude of $44.44^{\circ} \mathrm{E}$ ) in the period between May-October 2018. The solar air collector testes procedure has several steps as below: adjusting the experimental rig for the cover height of $20 \mathrm{~cm}$ inclination angle of $30^{\circ}$ and thermocouples at the center line position of the collector. Placing the experimental rig in the test location with facing the south orientation before $7 \mathrm{AM}$ in about hour and check the readings in all thermometers.

At $7 \mathrm{AM}$, record the measurements of twenty eight readings of temperatures in seven thermometers, the solar irradiance, temperatures of the absorber plate and glass cover, inlet and outlet temperatures to/from the collector, inlet and outlet air velocity to/from the collector. Repeating the procedure in point 3 for hours from 8 AM-3 PM. Repeating the procedure in points $1-4$ for the tilt angles of $45^{\circ}, 60^{\circ}, 70^{\circ}$. Repeating the procedures in points $1-5$ for the collector height of $10 \mathrm{~cm}$ case.

Error analysis: Error analysis for the obtained measurements was carried out. The calculations demonstrated that the deviation of $2.2 \%$ in the efficiency of the solar air heater of $64.2 \%$ was obtained for the measurements of the solar radiation of $707 \mathrm{Wm}^{-2}$, air velocity of $0.6 \mathrm{msec}^{-1}$ and temperature difference of $4.2^{\circ} \mathrm{C}$.

\section{RESULTS AND DISCUSSION}

Meteorological data: The total solar radiation for most test cases was measured. The intensity of the solar radiation was measured by the solar meter. Figure 3 shows the variation of the solar radiation measurements with time for the period from 17-21th May 2018 and for different tilt angles. The figure shows the intensity of solar radiation increases steadily with time and reached peak values at the mid-day then decreases steadily with time as the sun goes down in the late afternoon. When the results compared for different angles, it is shown that the tilt angle of $30^{\circ}$ has the best radiation received by the collector while the lowestreceived radiation was occurred at the angle of $75^{\circ}$. It is observed that the maximum solar intensity received is $921 \mathrm{~W} \mathrm{~m}^{-2}$ at the angle of $30^{\circ}$ due to the solar orientation. The results of solar radiation decrease when the tilt angles increase from $30^{\circ}-75^{\circ}$.

Absorber temperature: The temperature of the plate was measured by infrared thermometer. Figure 4 presents the mean temperature distribution of the absorber plate during the test time for different tilt angles and different heights. The temperature of the plate is low at $7 \mathrm{AM}$ and then gradually increases until reaches the peak at the midday and then decreases gradually to the end time of the test at $3 \mathrm{PM}$. The higher temperature gradient is occurring at the tilt angle of $30^{\circ}$ due to the compatibility with the received solar radiation. The results decrease when the tilt angles increase from $30^{\circ}-75^{\circ}$. Figure 4 shows the measurements for the height $10 \mathrm{~cm}$, the higher value of the mean temperature of $99.9^{\circ} \mathrm{C}$ was measured at midday time for the tilt angle of $30^{\circ}$. Figure 5 shows the measurements for the height $20 \mathrm{~cm}$ where more air enters the collector and cools the plate then reducing the plate temperature.

Temperatures distribution for all levels in the collector: The thermocouples within the solar air collector were distributed at different positions where 


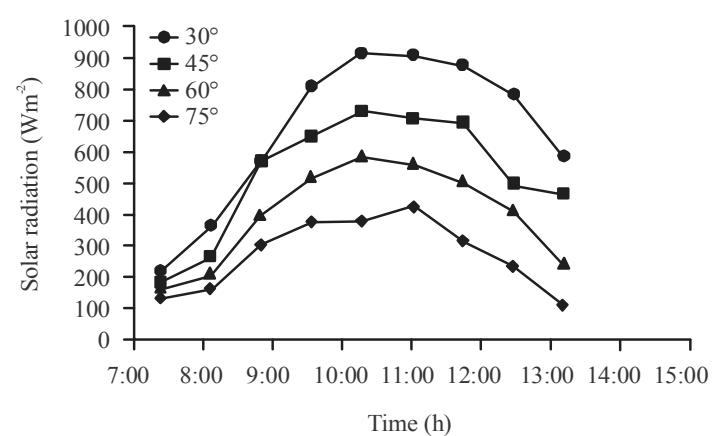

Fig. 3: Variation of solar radiation intensity with time for different tilt angles

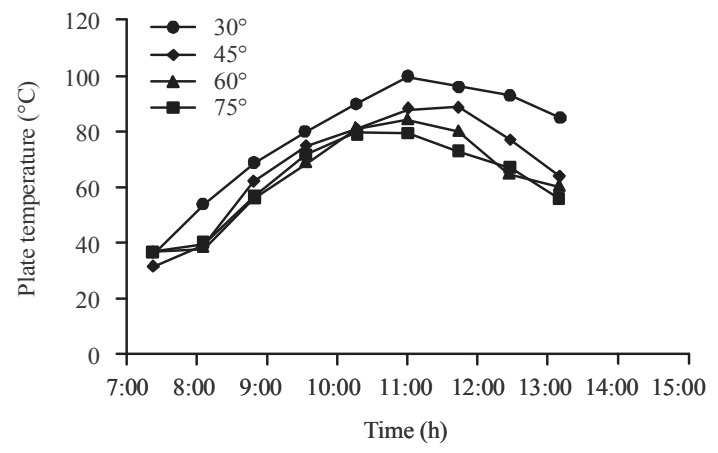

Fig. 4: Distribution of mean plate temperature with time for height of $10 \mathrm{~cm}$ and different tilt angles

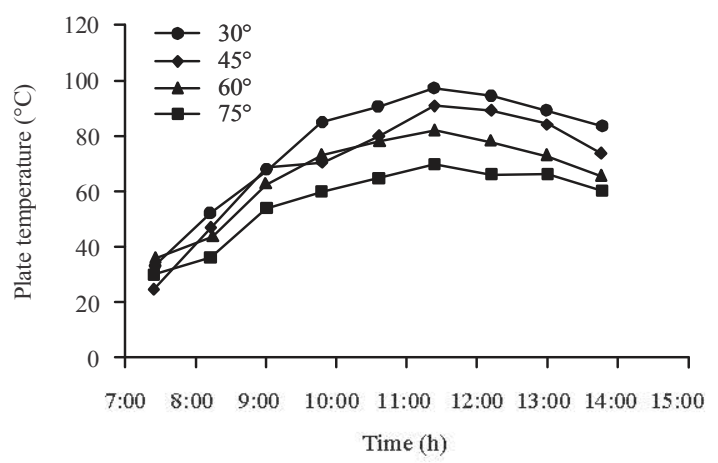

Fig. 5: Distribution of mean plate temperature with time for height of $20 \mathrm{~cm}$ and different tilt angles

airflow temperatures were measured in four levels. Figure 6 shows the temperatures distribution for four levels height of 2, 4, 6 and $8 \mathrm{~cm}$ above the absorber plate, the collector height of $10 \mathrm{~cm}$, tilt angle of $60^{\circ}$ and mean plate temperature of $65^{\circ} \mathrm{C}$ at the time of $2 \mathrm{PM}$. The figure also shows the temperatures of airflow are distributing along the collector where the same temperatures measure at entrance and exit to/from the collector. Therefore, the results show temperatures gradient vertically from the level $2 \mathrm{~cm}$ at higher temperature to the level $8 \mathrm{~cm}$ at lower

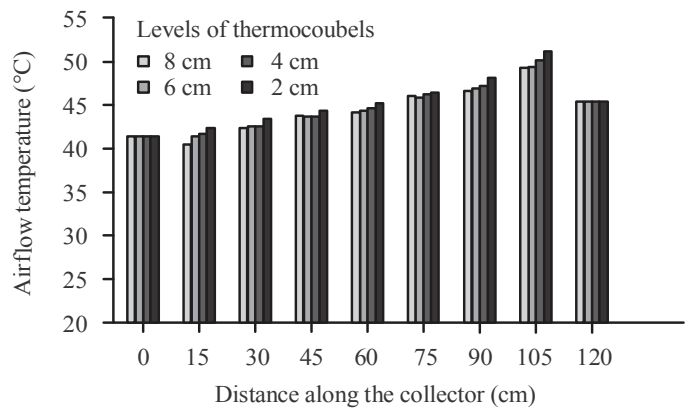

Fig. 6: Temperature distribution along the solar air collector for the four levels within the collector height of $10 \mathrm{~cm}$ and tilt angle of $60^{\circ}$

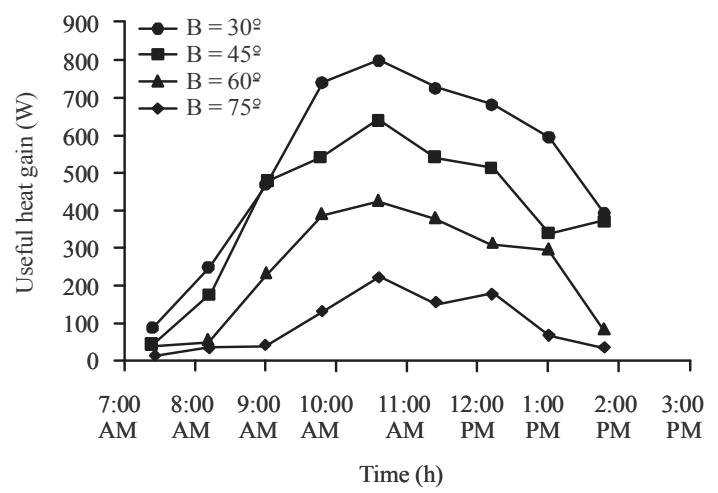

Fig. 7: Variation of useful heat gain with time for height of $10 \mathrm{~cm}$ and different tilt angles

temperature. While, temperatures distribution increasing when the distance along the collector increase from $15-105 \mathrm{~cm}$ due to heat transfer from the absorber plate to airflow.

Useful heat gain: A significant parameter influence the solar air collector performance is the useful heat gain, $Q_{u}$ which is based on the values of absorbed solar radiation, the collector overall loss coefficient, the measured plate and ambient air temperatures and determined by Eq. 1:

$$
\mathrm{Q}_{\mathrm{u}}=\mathrm{A}_{\mathrm{c}}\left[\mathrm{S}-\mathrm{U}_{\mathrm{L}}\left(\mathrm{T}_{\mathrm{p}}-\mathrm{T}_{\mathrm{a}}\right)\right]
$$

Where:

$A_{C}$ : The surface area of the collector

$\mathrm{T}_{\mathrm{p}}$ : Mean plate temperature

$\mathrm{T}_{\mathrm{a}}:$ Ambient air temperature

$\mathrm{S}$ : Absorbed solar radiation

$\mathrm{U}_{\mathrm{L}}$ : The overall loss coefficient

Figure 7 and 8 shows the variation of useful heat gain with time for different tilt angles and height of 10 and $20 \mathrm{~cm}$, respectively. The figure shows the useful heat gain increases and reaches the maximum value 


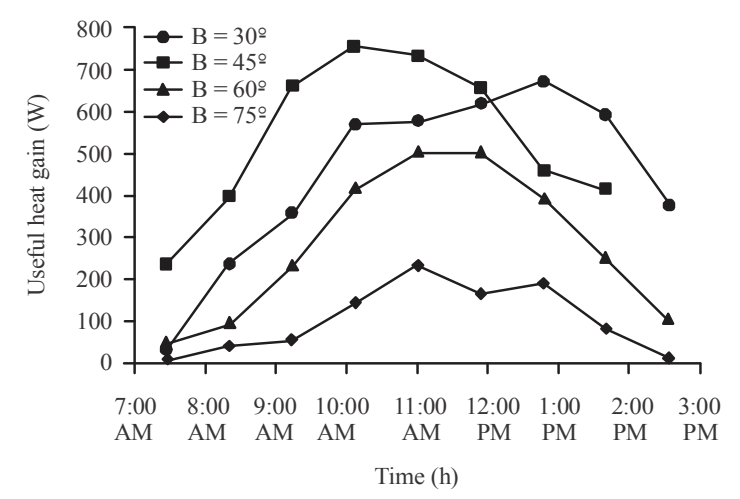

Fig. 8: Variation of use full heat guan with time for height of $20 \mathrm{~cm}$ and different tilt angles

around the noon and then decreases due to the solar radiation variation. The results decrease when the tilt angles increase from $30^{\circ}-75^{\circ}$. The figures appear that the higher values of the heat gain for the height of $10 \mathrm{~cm}$ occur at the tilt angle of $30^{\circ}$ while the higher values of the heat gain for the height of $20 \mathrm{~cm}$ occur at the tilt angle of $45^{\circ}$. The reason dates back to the solar radiation falling at the test day which effects the absorbed solar radiation by the plate.

Thermal efficiency of the collector: Thermal efficiency is a dimensionless quantity of the ratio of the useful heat gain as an output energy to the total radiation incidence on the collector as an input energy which described by Eq. 2 . The thermal efficiency represents the thermal process evaluation in the solar air collector which varies with time and the solar radiation:

$$
\eta=\frac{Q_{u}}{A_{c} I_{T}}
$$

Where:

$\mathrm{Q}_{\mathrm{u}}$ : Useful heat gain

$\mathrm{I}_{\mathrm{T}} \quad$ : Total solar radiation incidence

Figure 9 and 10 shows the variation of the thermal efficiency with time for different tilt angles and height of 10 and $20 \mathrm{~cm}$, respectively. The figure shows that the thermal efficiency increases from the $7 \mathrm{AM}$ to reach the maximum value before the noon and then decreases until 3 PM. The results decrease when the tilt angles increase from $30^{\circ}-75^{\circ}$. The maximum efficiency of $54 \%$ occurs for the tilt angle of $30^{\circ}$ and height of $10 \mathrm{~cm}$ while the maximum efficiency of $52 \%$ occurs for the tilt angle of $45^{\circ}$ and height of $20 \mathrm{~cm}$. A noticeable result for the tilt angle of $30^{\circ}$ was revealed where the thermal efficiency for the height of $10 \mathrm{~cm}$ is higher than that for the height of $20 \mathrm{~cm}$.

Figure 11 and 12 shows the effect of the measured solar radiation on the thermal efficiency for different tilt

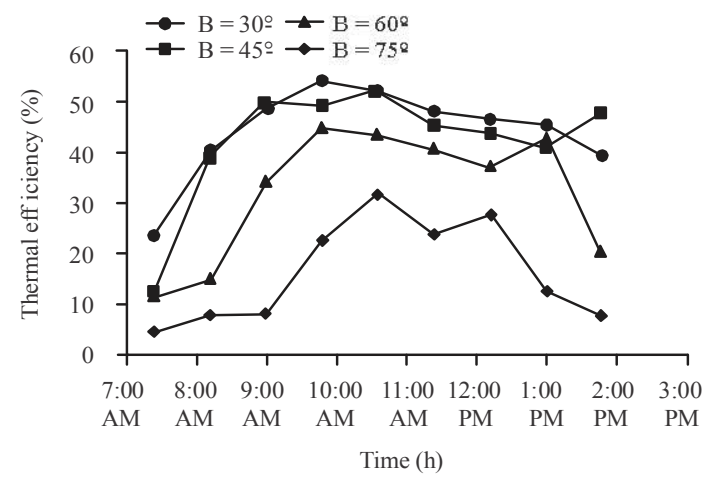

Fig. 9: Variation of thermal efficiency with time for height of $10 \mathrm{~cm}$ and different tilt angles

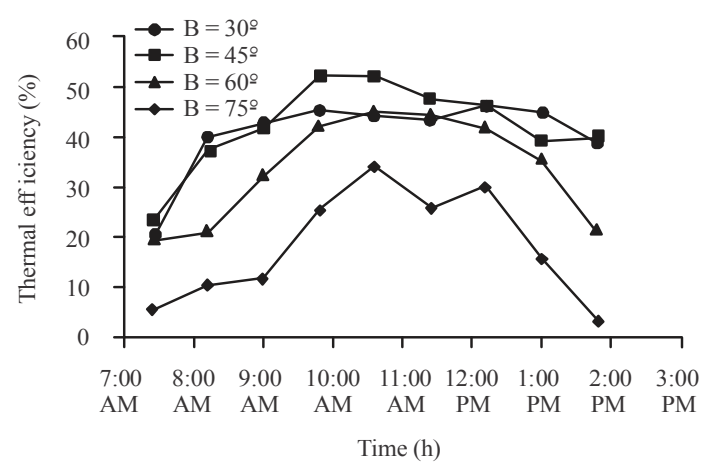

Fig. 10: Variation of thermal efficiency with time for height of $20 \mathrm{~cm}$ and different tilt angles

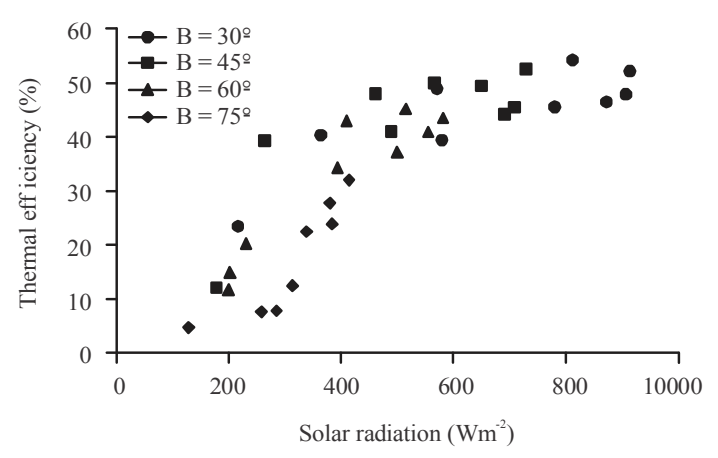

Fig. 11: Variation of thermal efficiency with solar radiation for height of $10 \mathrm{~cm}$ and different tilt angles

angles and height of 10 and $20 \mathrm{~cm}$, respectively. The figure shows the thermal efficiency increases when the solar radiation increase due to increasing the absorbed solar radiation and heat gain.

Natural convection flow: To evaluate the natural convection flow within the solar air collector, the dimensionless quantity of Rayleigh number $\mathrm{Ra}$ and 


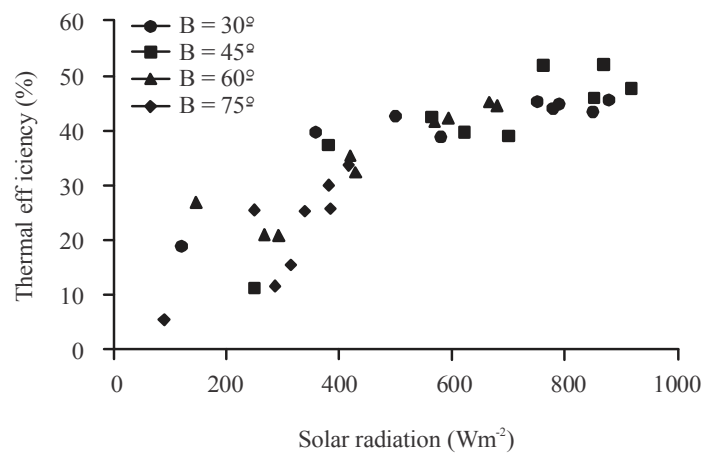

Fig. 12: Variation of thermal efficiency with solar radiation for height of $20 \mathrm{~cm}$ and different tilt angles

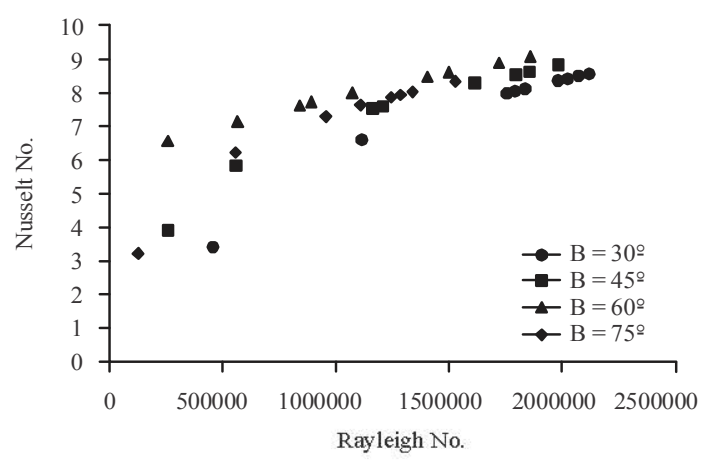

Fig. 13: Variation between $\mathrm{Nu}$ and $\mathrm{Ra}$ for height of $10 \mathrm{~cm}$ and different tilt angles

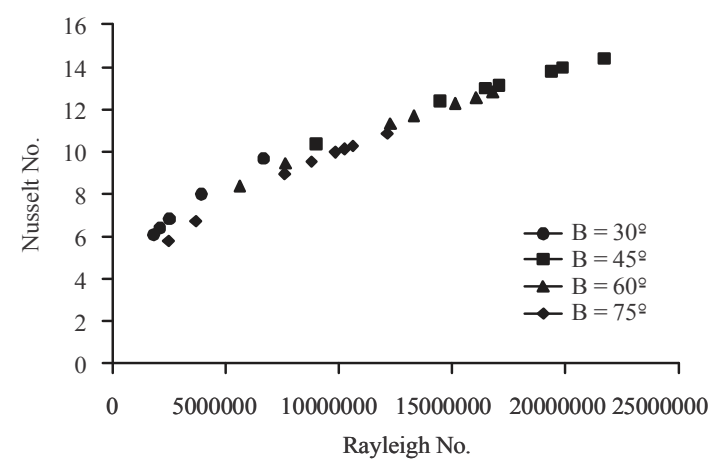

Fig. 14: Variation between $\mathrm{Nu}$ and $\mathrm{Ra}$ for height of 20 $\mathrm{cm}$ and different tilt angles

Nusselt number, $\mathrm{Nu}$ were utilized. Figure 13 and 14 shows the variation between $\mathrm{Nu}$ and $\mathrm{Ra}$ for different tilt angles and the height of 10 and $20 \mathrm{~cm}$, respectively. The $\mathrm{Nu}$ represents the ratio of convection to conduction heat transfer while the Ra represents the ratio of buoyancy to viscous forces. Therefore, the results show that the convection heat transfer increases when the buoyant force increase. For the height of $10 \mathrm{~cm}$, the results increase also when the tilt angles increase from $30^{\circ}-60^{\circ}$ then decreases

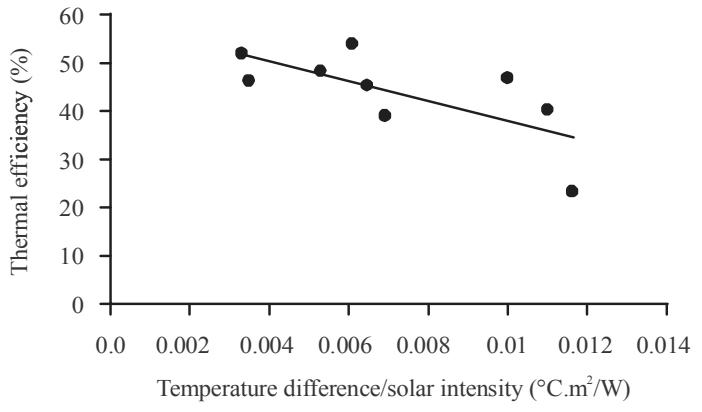

Fig. 15: Experimental efficiency of the flat plate solar air heater

when the tilt angle reach $75^{\circ}$ due to exceed the critical angle of $70^{\circ}$. While for the height of $20 \mathrm{~cm}$ the results increase when the tilt angles increase from $30^{\circ}-45^{\circ}$ then decrease when the tilt angles go toward $60^{\circ}$ and $75^{\circ}$ due to increasing the collector height and the tilt angle exceed the critical angle.

The collector efficiency: The performance of the solar air collector is evaluated by the relation between the thermal efficiency and the parameter of temperature difference to the solar radiation. Figure 15 shows the experimental efficiency of the flat plate solar air heater used in the present study. The figure shows decreasing the thermal efficiency when the temperature difference to the solar radiation increases. An experimental relationship of the performance behavior for the solar air heater was obtained and shown in Eq. 3:

$$
\eta=-2046.8\left(\Delta \mathrm{T}_{\mathrm{A}} \mathrm{A}_{\mathrm{C}} / \mathrm{I}_{\mathrm{T}}\right)+58.45
$$

\section{CONCLUSION}

The solar air heater has been fabricated by the dimensions of 120,100 and $20 \mathrm{~cm}$ in length, width and height, respectively. The solar air heater model parts, materials and tests procedure have been explained. The experimental model has been tested for the height of 10 and $20 \mathrm{~cm}$ and the tilt angles of $30^{\circ}, 45^{\circ}, 60^{\circ}$ and $75^{\circ}$. The following conclusions can be drawn from the obtained results: the flat plate solar air collector efficiently receives the solar energy and converts to the useful heat to produce natural convective flow.

The solar air collector supplies hot air up to $62^{\circ} \mathrm{C}$ for the height of $10 \mathrm{~cm}$ and the tilt angle of $30^{\circ}$ this temperature is acceptable for giving motivation of use this type of solar collector for heating space. Air temperatures within the solar air collector rise when the absorber plate temperature increases and when the collector height decreases.

In general, the results tend decrease when the tilt angles increase from $30^{\circ}-75^{\circ}$ and the height increase from 
$10-20 \mathrm{~cm}$. The thermal efficiency increases when the solar radiation increases. The convection heat transfer in the collector increases when the buoyant force of the natural flow increase.

\section{REFERENCES}

Aboltins, A. and J. Palabinskis, 2011. Investigations of heating process and absorber materials in air heating collector. Proceedings of the World Renewable Energy Congress-Sweden, May 8-13, 2011, Linkoping University Electronic Press, Linkoping, Sweden, ISBN:978-91-7393-070-3, pp: 3991-3998.

Aboltins, A., J. Palabinskis, A. Lauva and G. Ruskis, 2009. Investigations of air solar collector efficiency. Eng. Rural Dev., 1: 171-175.

Aboul-Enein, S., A.A. El-Sebaii, M.R.I. Ramadan and H.G. El-Gohary, 2000. Parametric study of a solar air heater with and without thermal storage for solar drying applications. Renewable Energy, 21: 505-522.

Amraoui, M.A. and K. Aliane, 2018. Three-dimensional analysis of air flow in a flat plate solar collector. Periodica Polytech. Mech. Eng., 62: 126-135.

Esmailie, F., H. Ghadamian and M. Aminy, 2014. Modeling and simulation of a solar flat plate collector as an air heater considering energy efficiency. Mech. Ind., 15: 455-464.
John, A.D. and A.B. William, 2013. Solar Engineering of Thermal Processes. John Wiley \& Sons, Hoboken, New Jersey, ISBN:978-1-118-43348-5, Pages: 910.

Joudi, K.A. and A.A. Farhan, 2014. Greenhouse heating by solar air heaters on the roof. Renewable Energy, 72: 406-414.

Kalogirou, S.A., 2004. Solar thermal collectors and applications. Prog. Energy Combust. Sci., 30: 231-295.

Palabinskis, J., A. Aboltins, A. Lauva and N. Karpova-Sadigova, 2008. The comparative material investigations of solar collector. Agron. Res., 6: 255-261.

Ruskis, G., A. Aboltins and J. Palabinskis, 2011. Different material investigations in air-heating flat-plate solar collector. Eng. Rural Dev. Proc., 10: $330-335$.

Sayigh, A.A.M., 2012. Solar Energy Engineering. Academic Press Inc., Cambridge, Massachusetts, USA., ISBN:9780323147095, Pages: 526.

Ucar, A. and M. Inalli, 2006. Thermal and exergy analysis of solar air collectors with passive augmentation techniques. Intl. Commun. Heat Mass Transfer, 33: 1281-1290.

Wang, L., Y. Man, S. Shi and Z. Wang, 2017. Research on structure optimal design of solar air collector. Procedia Eng., 205: 2049-2054.

Yang, M., P. Wang, X. Yang and M. Shan, 2012. Experimental analysis on thermal performance of a solar air collector with a single pass. Build. Environ., 56: 361-369. 